\section{EXTRACT TEETH WITH WRIST MOVEMENT ONLY}

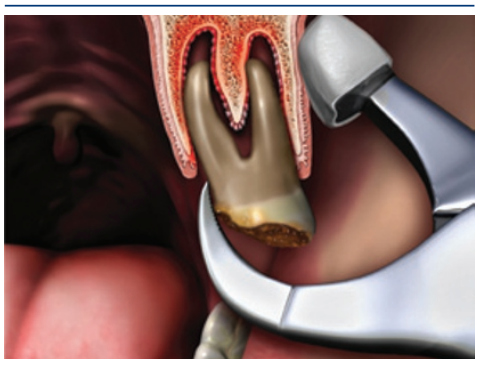

New Molar Physics Forceps are specifically designed to facilitate easier extractions of $6 \mathrm{~s}, 7 \mathrm{~s}$ and 8s. Featuring a slimline buccal buffer for easier access there are just two forceps in the set, one for the upper left and lower right quadrant and one for the other two. The new Molar Physics Forceps can also be used to extract teeth palatally, when palatal caries makes a conventional buccal extraction more challenging.

Physics Forceps enable dentists to extract teeth quicker and with less trauma for the patient. They dramatically reduce the amount of time required to extract teeth and make the whole procedure much more comfortable and pleasant for both the operator and patient.

They have a revolutionary 'beak and bumper' design that enables dentists to extract teeth using wrist movement only. Dramatically reducing the stress and strain experienced by patients, they also help preserve the buccal plate of bone, which is vital for the patient's long term dental health and success of future treatment options.

Physics Forceps are supplied with a training DVD which explains the easy to learn physics extraction technique. They are also supplied with a 60 day money back guarantee (subject to restock charge) and a ten-year warranty following customer registration.

The standard Physics Forceps and New Molar Set can be purchased as a Combi-Set (six instruments) at a special price for a limited period.

Call 01380734990 or visit www.generalmedical.co.uk.

\section{SEE MORE CLEARLY IN 2014}

Carl Zeiss' range of dental loupes use high quality optics which ensure the outstanding vision and therefore, higher levels of care.

Using a pair of Carl Zeiss loupes will reduce the levels of fatigue that are usually incurred throughout longer procedures. Using a pair of Carl Zeiss' specially designed loupes means that excellent visualisation can be achieved whilst sat with a correct posture, allowing the user to treat patients without the worry of developing neck or back problems.

Available exclusively in the UK from Nuview, Carl Zeiss' range of loupes offer high quality visualisation and an approach to dental treatment that avoids strain and fatigue. From the EyeMag Pro to the TTL Teleloupe, Carl Zeiss offers only the very best in visualisation.

For more information please call Nuview on 01453 872266, email info@nuview-ltd.com or visit www.nuview.co.

\section{PRECISION MILLING CAPABILITIES}

The DWX-4 dental milling machine from Roland DG offers precision milling capabilities, exceptional ease of use and a compact, desktop footprint.

The DWX-4 is designed so that even first-time users of a digital milling machine can easily create precision prosthetics. The workflow is simple. After installing the material and burrs in the machine, the operator imports the required design into the production software. After just a few clicks, the data are sent to the DWX-4. The machine will take care of tool changes.

With a four-axis configuration that includes three XYZ axes and a rotary axis, the DWX-4 features an automatic tool changer (ATC) that changes milling tools as needed without interrupting the production process. Prosthetic parts such as crowns and bridges can be produced using standard block and pin-type dental materials, including Zirconia, PMMA and wax.

The DWX-4 is equipped with several features that ensure easy, flawless performance, including a status light that displays the progress of each job, and a tool-life management system that monitors tool usage and automatically notifies the user when a tool replacement is needed. An air blower prevents dust from building up in the milling area, and a negative ion generator virtually eliminates dust build-up for a clean milling area. The DWX-4 also sends users an email notification of any errors, or when a job is completed.

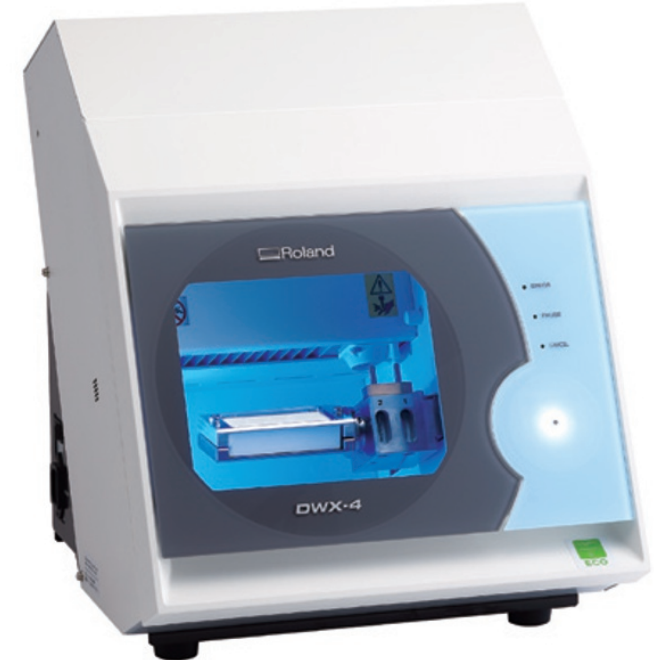

\title{
CAD DESIGN FOR CUSTOMISED ABUTMENTS
}

3Shape A/S has announced the official release of new capabilities in its Dental System to design two-piece customised abutments using the Straumann Variobase abutment connection - a premanufactured titanium interface.

3Shape has integrated an original Straumann library within its software supporting Straumann Bone Level and Tissue
Level implant systems. The library enables dental technicians to use 3Shape Abutment Designer to model two-piece abutments using a pre-manufactured titanium base with a customised zirconia abutment top. To manufacture the designed restoration, the original titanium base must be obtained from Straumann and the customised zirconia part can be milled locally in the lab or milling centre.

To find contact information for your area, see http://www.straumann.com/en/home/about-straumann/worldwide-locations.html. 